\title{
Particle Swarm Optimization based Economic Dispatch of Kerala Power System
}

\author{
K. Pramelakumari \\ Associate Professor \\ Electrical and Electronics \\ Engineering \\ Government Engineering College, \\ Thrissur
}

\author{
V. P. Jagathy Raj, PhD \\ Professor \\ School of Management Studies \\ Cochin University of Science and \\ Technology, Kochi-22
}

\author{
P. S. Sreejith, PhD \\ Professor and Dean \\ Faculty of Engineering \\ Cochin University of Science and \\ Technology, Kochi-22
}

\begin{abstract}
The economic load dispatch problem aims at controlling the committed generating unit outputs so as to meet the required load demand at minimum operating cost while satisfying the power demand and system equality and inequality constraints. The economic load dispatch is a non-linear constrained optimization method whose complexity increases when constraints such as system power balance constraints and generator constraints are considered. This paper describes the use of particle swarm optimization algorithm in finding out which combination of generators should be worked together in order to meet the required load demand at minimum operating cost
\end{abstract}

\section{Keywords}

Economic load dispatch, particle swarm optimization and power balance constraints.

\section{INTRODUCTION}

In economic dispatch, the objective is to calculate the output power of every generating unit, for a single period of time, so that all the demands are satisfied at the minimum cost, while satisfying different constraints of the model. Optimization is a nonlinear mathematical model of a real-world problem. In this paper, particle swarm optimization technique is utilized for economic load dispatch problem to find the generating units that minimize the generation cost while satisfying a set of constraints.

The major qualitative factors in power industry are frequency, voltage and stability. In the integrated environment, it is not possible to take a corrective action by Kerala to modify the grid frequency [1]. This will be more acute when the Southern Region is integrated to the rest of India through $800 \mathrm{kV}$ links. Voltage and stability are within the control of the grid operators, transmission and distribution managers, where optimization is possible. The cost aspect lies in the domain of system operators in the regulated power market. Since the hourly consumption of power is several thousands of MW even a single paise per MW saves several crores of Rupees to Kerala power economy [2].

The cost of supplying electricity to consumers can be divided in to demand costs and energy cost, compared to the common industrial classification of fixed and variable costs. Demand costs are the capacity related costs for generation, transmission and distribution and vary with the quality of plant and equipment and the associated investment. Energy costs are those which vary directly with the quantity of units generated [3].
This paper focuses on an economic dispatch of Kerala power system by the formulation of cost optimization problem and finding out solution through particle swarm optimization. The data collected from Kerala State Electricity Board Ltd., are used for the model representation which portrays a real physical problem. The data consists of varying operational and maintenance costs of different generators per hour on daily basis as well as hourly load generated from 50 generators in 17 stations across the State.

\section{KERALA POWER SYSTEM: THE NEED FOR OPTIMISATION}

The cost of power procurement alone works out at present $70 \%$ of the total revenue requirement of Kerala State Electricity Board Ltd (KSEB Ltd) depending on the availability of monsoon. This necessitates for framing an optimization strategy in the management of power system. To meet the increase in energy demand the KSEB Ltd has been heavily depending on the short-term market and energy exchanges, because new major hydel projects have not yet been materialized in the State due to various reasons. At present about 15 to $20 \%$ of the energy requirement of the State is being met from short-term market i.e., high dependence on costlier power [4]. Water is the only commercially viable source for power generation within the State to ensure reliability of supply as well as energy security addition in Kerala. The need for equipping Kerala Power System to meet the demands of the excepted explosive growth in the industrial sector is well recognized.

The cost of generation and power purchase are increased on account of the reduction in hydel availability and the consequent increase in demand and excessive energy prices of short-term markets, transmission constraints on importing power from outside the State, increase in cost of liquid fuel stations etc.

During 2016-17 the total capacity addition from all sources was 55.03MW. Total installed capacity of power in the State as on March 2017 is 2,961.11MW. Of which, hydel contributed the major share of 2,107.96 MW (71.19\%); while $718.46 \mathrm{MW}$ was contributed by thermal projects, $59.27 \mathrm{MW}$ from wind and 75.42MW from solar [5]. During 2017-18 the total installed capacity in Kerala was 2791.25 MW. Of which KSEB Ltd contribution was 2215.24MW and others 576.01MW.

The total energy consumption for a day as on $20^{\text {th }}$ Aug 2018 was 50.3843MU. The availability of energy from Central Generating Station was $20.99 \mathrm{MU}$ and purchase was 8.3512MU and energy from hydro was 21.04 MU. Evening peak on the same day was $3040 \mathrm{MW}$. The total availability 
was 2099.345 MW. The remaining 940.655MW was purchased. For this purchase Rs 16.931 crore was required for one day. That is, the KSEB Ltd was running at a loss. For reducing this loss, the imported power has to be reduced by using the optimization techniques.

\section{ECONOMIC LOAD DISPATCH PROBLEM FORMULATION}

The complex nature of generation of electricity signifies ample opportunity of improvement towards the optimal power generation solution. The demand of power system varies throughout the day and reaches a different peak value from one day to another. To satisfy this demand, to start-up and shut-down, a number of generating units at various power stations each day is needed [6]. The difficult task is to decide when and which generating units are to turn on and turn off together with minimizing the total cost. Similarly, the total generation must be equal to the forecasted demand of electricity. For reducing the generation cost, optimized scheduling for economic load dispatch is necessary. Thus, the economic dispatch is one of the most important problems to be solved in the operation and planning of a power system.

The primary objective of the electric power generation is to schedule the committed generating unit outputs so as to meet the required load demand at minimum operating cost while satisfying all unit and system constraints [7]. Extensive amount of power is drawn daily from external sources that are not under the authority of Kerala power system, despite the load being much lesser than the installed capacity. Hence, this economic dispatch formulation tries to reduce external import of power and attempts to introduce self-sustainability into Kerala power system.

In the traditional economic dispatch problem, the cost function for each generator has been approximately represented by a single quadratic function and is solved using mathematical programming based on the optimization techniques [8]. Lagrange Relaxation (LR) method is commonly used to solve large scaled unit commitment problems. LR has been successfully applied to the complex unit commit problem including various hard constraints (ramp rate constraints, minimum up and down time, etc.). Unit commitment is a nonlinear mixed integer optimization problem. It schedules the operation of the generating units as minimum operating cost satisfying the demand and other constraints. [9]

Based on the data obtained from KSEB Ltd and the Kerala State Electricity Regulatory Commission, the required parameters are made into an economic dispatch model. Figure 1 depicts the system structure of the proposed method.

g

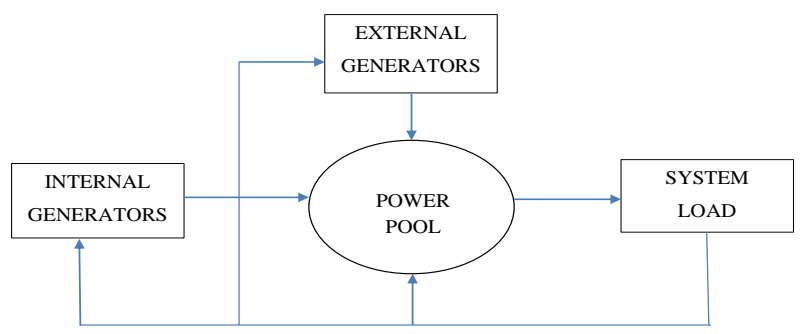

Fig .1: Power system structure

\subsection{Objective Function}

The objective function of the economic dispatch problem can be expressed in the following equation:

$\operatorname{Min}\left(F_{t}\right)=\sum_{i=1}^{N_{g}} F_{i}\left(P_{i}\right)$

The generation cost function $F_{i}\left(P_{i}\right)$ is usually expressed as a quadratic polynomial as in the equation (2) [10].

$$
\operatorname{Min}\left(F_{t}\right)=\sum_{i=1}^{N_{g}} \alpha_{i}+\beta_{i} P_{i}+\gamma_{i} P_{i}^{2}
$$

Where,

$N_{g}$ - Number of internal generators

$P_{i}$ - Load dispatch of $i^{\text {th }}$ generator at time $\mathrm{t}$

$\alpha_{i}, \beta_{i}, \gamma_{i}$ - Cost coefficients of $i^{t h}$ generator

Each generating unit has a unique production cost defined by its cost coefficients. Here the curve fitting method is used in order to find the cost coefficients $\alpha_{i}, \beta_{i}, \gamma_{i}$ by giving input as matrices of load in MW and cost in Rupees per hour. Curve fitting tool in MATLAB is used to obtain the value of cost coefficient.

\subsection{Constraints}

The objective function in equation (1) is minimized subjected to a set of constraints. The various constraints to be considered in the economic dispatch problem are: system power balance constraints and generator constraints. The major constraints considered are the following:

a) System power balance constraint is mathematically expressed as:

$$
\sum_{i=1}^{N_{g}}\left(P_{i, t}\right)=P_{L}(t)+P_{\text {loss }}(t)
$$

Where,

$P_{i, t}$ - the scheduled optimal generation of $i^{\text {th }}$ unit.

$N_{g}$ - the number of generators available for generating the load.

$P_{L}(t)$ - the active power load at time point $\mathrm{t}$.

$P_{\text {loss }}(t)$ - the estimated loss at time point, $\mathrm{t}$.

b) Generator constraint is expressed as in the equation below:

$$
P_{i, \min } \leq P_{i, t} \leq P_{i, \max }
$$

Where,

$P_{i, \min }$ - the minimum load generated from $i^{\text {th }}$ unit.

$P_{i, \max }$ - the maximum load generated from $i^{\text {th }}$ unit.

\section{PARTICLE SWARM OPTIMIZATION}

The Particle Swarm Optimization (PSO) algorithm was introduced by Kennedy and Eberhart in 1995. The original objective of this technique was to mathematically simulate the social behavior of bird flocks and fish schools. For developing the simulation was to model human social behavior, which is not identical to fish schooling or bird flocking. In PSO [11][13] the potential solutions, called particles, "fly" through the problem space by following some simple rules. All of the particles have fitness values based on their position and have velocities which direct the flight of the particles. PSO is initialized with a group of random particles (solutions), and then searches for optima by updating generations. In every iteration, each particle is updated by following two "best" values. The first one is the best solution (fitness) the particle has achieved so far. This value is called "pbest" or the individual particle best. Another "best" value that is tracked by the particle swarm optimizer is the best value obtained so far by any particle in the population. This best value is a global best and called "gbest" or the global best among all the 
considered particles, considering the current as well as all the previous iterations. After finding the two best values explained above, the particle updates its parameters, velocity and position with following equations (5) and (6):

$$
\begin{gathered}
V_{n}(k+1)=w * V_{n}(k)+c_{1} \cdot \operatorname{rand}_{1} \cdot\left(\text { Pbest }_{n}(k)-P_{n}(k)\right)+ \\
c_{2} \cdot \operatorname{rand}_{2} \cdot\left(G_{\text {best }}-P_{n}(k)\right) \\
P_{n}(k+1)=P_{n}(k)+V_{n}(k+1)
\end{gathered}
$$

Where, $w$ is the inertia coefficient which slows velocity over time; $V_{n}(k)$ is the $\mathrm{n}^{\text {th }}$ particle velocity after the $\mathrm{k}^{\text {th }}$ iteration; $P_{n}(k)$ is the current $\mathrm{n}^{\text {th }}$ particle position in the search space; pbest $_{n}(k)$ and gbest are the"personal" or individual best (describe the individuality) and global best (describing the social nature of the particle); rand 1 and rand $_{2}$ random numbers between $(0,1) ; c_{1}$ and $c_{2}$ are learning factors. The stop condition is usually the maximum number of allowed iterations for PSO to execute or the minimum error requirement. As with the other parameters, the stop condition depends on the problem to be optimized [14].

A total 50 generators are considered and particle of size 30 is selected. Also, a matrix of size $50 \times 30$ is initialized. For each of these generators, pbest and gbest are found in each iteration. Cost per unit is selected as pbest for each of the particles. The constraints explained in the system such as a) and b) are considered while optimizing the cost of production in each iteration. The algorithm used for this optimization includes the following steps:

Step 1: Read internal generation available for time t. Here 50 major generating stations are taken as internal generators as explained;

Step 2: Read cost coefficients $\alpha_{i}, \beta_{i}, \gamma_{i}$ that has been calculated beforehand using curve fitting tool;

Step 3: Initialize particle size, number of iteration and maximum error, learning

factors $\left(c_{1}, c_{2}\right)$ and inertia weight $(w)$. Define initial velocity and position of particles for each generating unit;

Step 4: Calculate dispatch and cost per unit and select cost per unit as pbest;

Step 5: Check maximum minimum conditions of dispatch from each unit;
Step 6: Select gbest (minimum of cost per unit);

Step 7: Update particle parameters;

Step 8: Calculate new dispatch and cost per unit and update pbest;

Step 9: Check maximum and minimum conditions of dispatch and update gbest;

Step 10: Check and enforce pattern of internal and external generations; and

Step 11: Increment time slot.

Go to step 9 .

In this work, PSO with time varying inertia weight (PSOTVIW) factor is used. The optimal solution is improved by varying the value of inertia weight from 0.4 to 0.9 . The entire methodology is summarized as a flow chart in figure 2 .

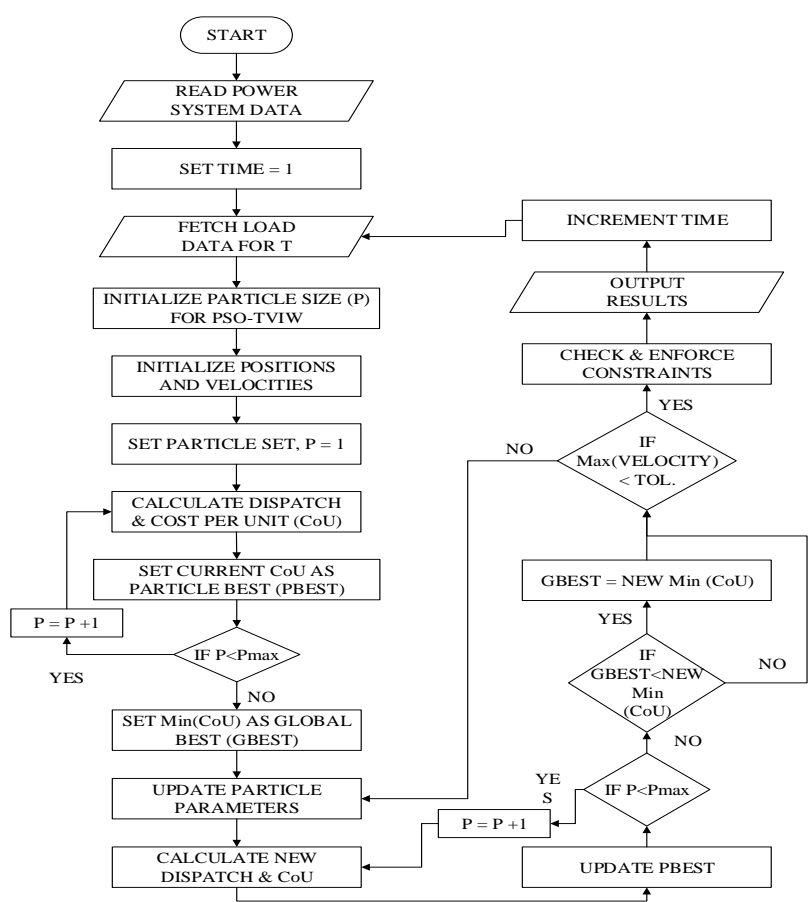

Fig.2: Flow chart for PSO based economic load dispatch 
Table.1: Cost function coefficients of 50 units system

\begin{tabular}{|c|c|c|c|c|}
\hline $\begin{array}{c}\text { Generating } \\
\text { Units }\end{array}$ & $\alpha \mathrm{Rs} / \mathrm{hr}$ & $\beta \mathrm{Rs} / \mathrm{MWhr}$ & $\gamma \mathrm{Rs} / \mathrm{MWhr}^{2}$ & P_Optimal \\
\hline 1 & 1744.7236 & 0 & 0.0000490787 & 99.404936 \\
\hline 2 & 1835.7919 & 0.00387579 & 0.0000930924 & 99.404936 \\
\hline 3 & 1056.9862 & 0.006459667 & 0.0001356974 & 99.404936 \\
\hline 4 & 1843.3758 & 0.001937896 & 0.0002987879 & 99.404936 \\
\hline 5 & 1562.3592 & 0.001937896 & 0.000409986 & 99.404936 \\
\hline 6 & 1027.5404 & 0.001937896 & 0.000459206 & 99.404936 \\
\hline 7 & 1208.4982 & 0.0019479356 & 0.0009618129 & 42.055934 \\
\hline 8 & 1476.8815 & 0.0038958706 & 0.0014026736 & 42.055934 \\
\hline 9 & 1887.5068 & 0.0038958706 & 0.0017053512 & 42.055934 \\
\hline 10 & 1894.8885 & 0.0038958706 & 0.001776971 & 42.055934 \\
\hline 11 & 1087.6130 & 0.0038958706 & 0.0008436269 & 45.879201 \\
\hline 12 & 1900.5927 & 0.003895876 & 0.0011952770 & 45.879201 \\
\hline 13 & 1887.1669 & 0.000481958 & -0.0001607599 & 2.6762867 \\
\hline 14 & 1415.3756 & 0.002891467 & -0.0059924722 & 2.6762867 \\
\hline 15 & 1730.2804 & 0.00192764237 & -0.0036757594 & 2.6762867 \\
\hline 16 & 1071.8863 & 0.005799594728 & 0.0004526858 & 45.879201 \\
\hline 17 & 1351.7612 & 0 & 0.0015765130 & 45.879201 \\
\hline 18 & 1845.7355 & 0.00231983787 & 0.0023847449 & 45.879201 \\
\hline 19 & 1722.2073 & 0.022905835 & -0.0007750620 & 13.381433 \\
\hline 20 & 1889.4924 & 0 & -0.000473742972 & 13.381433 \\
\hline 21 & 1585.7407 & 0.0152705575 & -0.00007071814 & 13.381433 \\
\hline 22 & 965.71167 & 0.00416582519 & -0.00034552462 & 19.116334 \\
\hline 23 & 1779.1293 & 0 & -0.0027212523 & 28.674501 \\
\hline 24 & 1863.9932 & 0 & -0.00226187310 & 28.674501 \\
\hline 25 & 1608.7351 & 0.0005671898 & -0.00415059163 & 3.8232667 \\
\hline 26 & 1687.7401 & 0.0017015687 & -0.00876417201 & 3.8232667 \\
\hline 27 & 1673.1324 & 0.0017015687 & -0.0017019061 & 3.8232667 \\
\hline 28 & 1322.2270 & 0 & -0.0016889454 & 5.7349001 \\
\hline 29 & 1585.4778 & 0.00226875857 & -0.0080733552 & 5.7349001 \\
\hline 30 & 1101.1866 & 0.0034031377 & 0.0049812530 & 5.7349001 \\
\hline 31 & 1636.0469 & 0.0064610707 & -0.0016276787 & 9.1758403 \\
\hline 32 & 961.83284 & 0.00403816887 & -0.00883832794 & 9.1758403 \\
\hline 33 & 1206.9229 & 0.000470438 & -0.00126463984 & 9.1758403 \\
\hline 34 & 976.1713 & 0,0001974298 & 0.000739784736 & 9.1758403 \\
\hline 35 & 1027.1317 & 0.0010349637 & 0.000201753141 & 12.234453 \\
\hline 36 & 1753.4578 & 0.00075270098 & 0.000472815265 & 12.234453 \\
\hline 37 & 1624.8286 & 0.00019742978 & 0.0008590879 & 6.1172268 \\
\hline 38 & 1247.0994 & 0 & 0.0001993692 & 6.1172268 \\
\hline 39 & 1880.2220 & 0.00019742978 & 0.000562894 & 6.1172268 \\
\hline 40 & 964.44608 & 0.001579438368 & 0.0001062650 & 6.1172268 \\
\hline 41 & 1368.7443 & 0.0001237119 & -0.0001188750 & 12.234453 \\
\hline 42 & 1311.5584 & 0 & 0.0001604344 & 13.763760 \\
\hline 43 & 1695.5167 & 0 & -0.0004649355 & 13.763760 \\
\hline 44 & 1725.1999 & 0.00983596057 & 0.0002980414 & 13.763760 \\
\hline 45 & 1116.8726 & 0.0009437548 & 0.0002663307 & 19.116334 \\
\hline 46 & 1419.7644 & 0.0005243078 & 0.000277830 & 19.116334 \\
\hline 47 & 1375.5862 & 0.0020972317 & 0.000435668 & 19.116334 \\
\hline 48 & 1576.3130 & 0.0029361237 & 0.0000163413 & 38.232667 \\
\hline 49 & 1639.3648 & 0.0016777857 & 0.0000142703 & 38.232667 \\
\hline 50 & 1684.6866 & 0.0016777857 & 0.0000235636 & 38.232667 \\
\hline
\end{tabular}




\begin{tabular}{|c|c|c|c|c|c|c|c|}
\hline $\begin{array}{l}\text { No. of } \\
\text { Days }\end{array}$ & $\begin{array}{l}\text { April,2015 Actual } \\
\text { Power (Hydro)MW }\end{array}$ & $\begin{array}{c}\text { Optimised } \\
\text { power } \\
\text { (Hydro)MW }\end{array}$ & $\begin{array}{l}\text { Demand/Consumpti } \\
\text { on (MW) }\end{array}$ & $\begin{array}{l}\text { Import power } \\
\text { (MW) }\end{array}$ & $\begin{array}{l}\text { Optimised } \\
\text { cost (Rs.) }\end{array}$ & $\begin{array}{c}\text { Cost of } \\
\text { imported } \\
\text { power (Rs.) }\end{array}$ & $\begin{array}{c}\text { Cost saving } \\
\text { (Rs.) }\end{array}$ \\
\hline 1 & 583.375 & 1869.294 & 2348.833542 & 1765.458542 & 41722642.08 & 155925298.4 & 114202656.3 \\
\hline 2 & 696.9483 & 1884.776 & 2577.406667 & 1880.458367 & 42068200.32 & 166082082.9 & 124013882.6 \\
\hline 3 & 707.0006 & 1895.793 & 2586.229792 & 1879.229192 & 42314099.76 & 165973522.2 & 123659422.4 \\
\hline 4 & 726.7267 & 1900.361 & 2588.342917 & 1861.616217 & 42416057.52 & 164417944.3 & 122001886.7 \\
\hline 5 & 805.2898 & 1871.402 & 2608.727292 & 1803.437492 & 41769692.64 & 159279599.3 & 117509906.6 \\
\hline 6 & 780.9167 & 1894.732 & 2571.4375 & 1790.5208 & 42290418.24 & 158138797.1 & 115848378.8 \\
\hline 7 & 1108.91 & 1960.7286 & 2869.769792 & 1760.859792 & 43763462.35 & 155519136.8 & 111755674.4 \\
\hline 8 & 691.1335 & 1911.06 & 2517.737708 & 1826.604208 & 42654859.2 & 161325683.7 & 118670824.5 \\
\hline 9 & 509.6863 & 1911.991 & 2344.18625 & 1834.49995 & 42675639.12 & 162023035.6 & 119347396.5 \\
\hline 10 & 772.0631 & 1898.427 & 2562.854792 & 1790.791692 & 42372890.64 & 158162722.2 & 115789831.6 \\
\hline 11 & 813.3913 & 1885.964 & 2663.89125 & 1850.49995 & 42094716.48 & 163436155.6 & 121341439.1 \\
\hline 12 & 897.6962 & 1879.037 & 2680.905 & 1783.2088 & 41940105.84 & 157493001.2 & 115552895.4 \\
\hline 13 & 987.4973 & 1892.007 & 2870.472292 & 1882.974992 & 42229596.24 & 166304351.3 & 124074755 \\
\hline 14 & 987.4973 & 1918.799 & 2729.893125 & 1742.395825 & 42827593.68 & 153888399.3 & 111060805.6 \\
\hline 15 & 1046.674 & 1909.516 & 2792.194792 & 1745.520792 & 42620397.12 & 154164396.3 & 111543999.2 \\
\hline 16 & 929.3985 & 1873.7701 & 2642.231875 & 1712.833375 & 41822548.63 & 151277443.7 & 109454895 \\
\hline 17 & 1065.873 & 1947.4246 & 2834.908125 & 1769.035125 & 43466517.07 & 156241182.2 & 112774665.2 \\
\hline 18 & 811.3067 & 1908.314 & 2519.056667 & 1707.749967 & 42593568.48 & 150828477.1 & 108234908.6 \\
\hline 19 & 658.4935 & 1881.351 & 2372.264375 & 1713.770875 & 41991754.32 & 151360243.7 & 109368489.4 \\
\hline 20 & 710.1985 & 1887.489 & 2520.136042 & 1809.937542 & 42128754.48 & 159853683.7 & 117724929.2 \\
\hline 21 & 821.3923 & 1910.71 & 2652.996458 & 1831.604158 & 42647047.2 & 161767279.3 & 119120232.1 \\
\hline 22 & 815.155 & 1838.3188 & 2831.83125 & 2016.67625 & 41031275.62 & 178112846.4 & 137081570.8 \\
\hline 23 & 1014.736 & 1901.868 & 2756.902917 & 1742.166917 & 42449693.76 & 153868182.1 & 111418488.3 \\
\hline 24 & 995.3971 & 1883.575 & 2766.355417 & 1770.958317 & 42041394 & 156411038.5 & 114369644.5 \\
\hline 25 & 1046.156 & 1893.948 & 2792.760625 & 1746.604625 & 42272919.36 & 154260120.5 & 111987201.1 \\
\hline 26 & 1004.426 & 1872.152 & 2764.321458 & 1759.895458 & 41786432.64 & 155433966.9 & 113647534.2 \\
\hline 27 & 1096.679 & 1902.131 & 2578.4675 & 1481.7885 & 42455563.92 & 130871560.3 & 88415996.4 \\
\hline 28 & 1098.085 & 1907.211 & 2804.772708 & 1706.687708 & 42568949.52 & 150734658.4 & 108165708.9 \\
\hline 29 & 1148.448 & 1911.751 & 2879.8225 & 1731.3745 & 42670282.32 & 152914995.8 & 110244713.5 \\
\hline 30 & 1149.784 & 1914.541 & 2869.700833 & 1719.916833 & 42732555.12 & 151903054.7 & 109170499.6 \\
\hline
\end{tabular}

Table.2: The optimum cost corresponding to optimum scheduling for the month April 2015

\section{RESULTS AND DISCUSSION}

\section{1: Case I - PSO based hourly economic scheduling and cumulative daily optimal cost evaluation}

The implementation of the PSO algorithm and problem formulation is done using MATLAB. Short term and midterm load of the month April 2015 data is used for getting optimum cost withPSO. The load for the time slot of $00.30 \mathrm{hrs}$ to $24.00 \mathrm{hrs}$ of is considered. Table 1 shows the cost coefficient values of $\alpha_{i}, \beta_{i}, \gamma_{i}$ of 50 generators and the optimum generated load. In this study, the steps of the algorithm explained above are implemented by using the load of $1^{\text {st }}$ April 2015 in one hour and the results are shown in the table 1 . The cost per unit of internal generation is 93 paise per $\mathrm{kWhr}$ and cost per unit of imported power is rupees 3.68 per
kWhr respectively. From the results obtained, it can be found that hydro generation can be increased by $57.68 \%$ and import of power can be reduced by $63.72 \%$. Thus, there is a daily saving of Rupees 1356475.92 per hour.

\section{2: Case II - PSO based hourly economic scheduling and cumulative monthly optimal cost evaluation}

The generation cost evaluation of 30 days can be done by changing the time slot from 00.00 to 24.00 hours in steps of 30 minutes time slots. The actual internal power, optimized power, demand in MW, imported power in MW (purchased power), cost of optimized power, cost of imported power and cost savings are shown in table 2 . Fig 3 shows the optimum 
cost corresponding to optimum scheduling of April 2015. Fig 4 shows the optimum power corresponding to actual power which is inferred from the table 2 .

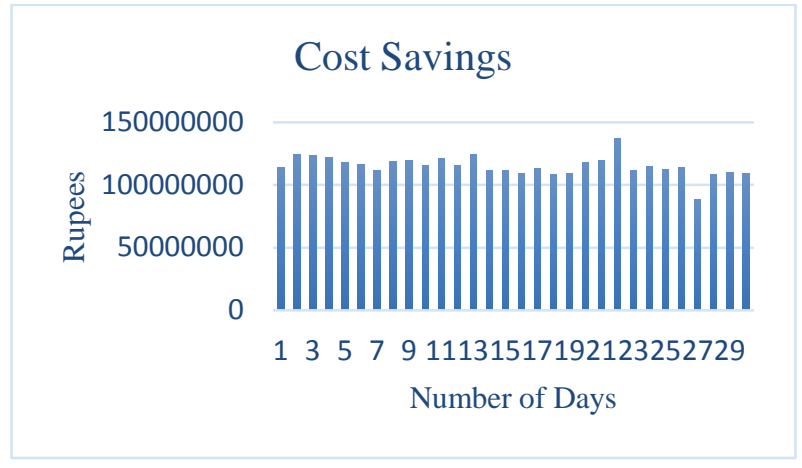

Fig.3: Graphical representation of table 2.

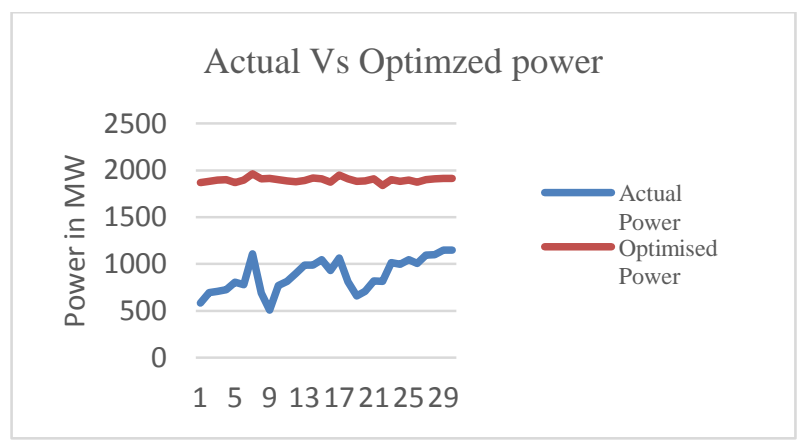

Fig. 4: Graphical representation of actual and optimized power.

\section{CONCLUSION}

In this paper, the cost optimization of Kerala power system based on economic load dispatch has been done. The PSO is used as a tool for solving the economic load dispatch problem. PSO-TVIW based optimum scheduling with STLF (for one day and one month) data has been carried out. The algorithm used in this program and the results in each are described in detail. Half-hourly economic scheduling and cumulative daily and monthly optimal cost evaluation and steps involved in monthly cost calculation are also described. It is clear from the result that the actual expenditure occurred in KSEB Ltd is higher than that obtained by using PSO. That means, the total production cost of KSEB Ltd can be minimized by applying PSO-TVIW.

\section{REFERENCES}

[1] Economic Review, 1997, State Planning Board, Government of Kerala.
[2] Lee, K. Y., Y. T. Cha, and J. H. Park. "Short-term Load Forecasting Using an Artificial Neural Network."IEEE Transactions on Power Systems 7, no. 1 (1992): 124-132.

[3] Wood, Allen J., and Bruce F. Wollenberg. Power Generation, Operation, and Control. John Wiley \& Sons, 2007.

[4] Kerala State Electricity Regulatory Commission Orders, April 2017

[5] Economic Review, 2017, State Planning Board, Government of Kerala.

[6] Jaini, A., I. Musirin, N. Aminudin, M. M. Othman, and TK A. Rahman. "Particle Swarm Optimization (PSO) Technique in Economic Power Dispatch Problems." In Power Engineering and Optimization Conference (PEOCO), 2010 4th International, pp. 308-312. IEEE, 2010.

[7] Hamdan, Norhamimi, Musse Mohamud Ahmed, and Ismail Hassan. "New Costs Optimization Concepts for Unit Commitment and Economic Load Dispatch in Large Scale Power Systems." In TENCON 2004. 2004 IEEE Region 10 Conference, vol. 100, pp. 480-483. IEEE, 2004.

[8] Dasgupta, Koustav, and Sumit Banerjee. "An Analysis of Economic Load Dispatch Using Different Algorithms." In Non-Conventional Energy (ICONCE), 2014 1st International Conference on, pp. 216-219. IEEE, 2014.

[9] Ahmed, M. M., and I. Hassan. "Costs Optimization for Unit Commitment and Economic Load Dispatch in Large Scale Power Systems." In Power and Energy Conference, 2004. Proceedings. National, pp. 190-194. IEEE, 2004.

[10] Gaing, Zwe-Lee. "Particle Swarm Optimization to Solving the Economic Dispatch Considering the Generator Constraints." IEEE Transactions on Power Systems 18, no. 3 (2003): 1187-1195.

[11] Eberhart, Russell, and James Kennedy. "A New Optimizer Using Particle Swarm Theory." In Micro Machine and Human Science, 1995.MHS'95., Proceedings of the Sixth International Symposium, pp. 39-43. IEEE, 1995

[12] Hu, Xiaohui, and Russell Eberhart. "Solving Constrained Nonlinear Optimization Problems with Particle Swarm Optimization." In Proceedings of the Sixth World Multiconference on Systemics, Cybernetics and Informatics, vol. 5, pp. 203-206. 2002.

[13] Eberhart, Russell C., and Yuhui Shi. "Guest Editorial Special Issue on Particle Swarm Optimization." IEEE Transactions on Evolutionary Computation 8, no. 3 (2004): 201-203.

[14] Lee, Kwang Y., and Mohamed A. El-Sharkawi, eds. Modern Heuristic Optimization Techniques: Theory and Applications to Power Systems. Vol. 39. John Wiley \& Sons, 2008

[15] Park, J. H., Y. S. Kim, I. K. Eom, and K. Y. Lee. "Economic Load Dispatch for Piecewise Quadratic Cost Function Using Hopfield Neural Network." IEEE Transactions on Power Systems 8, no. 3 (1993): 10301038 